SHORT REPORT

\title{
A feasibility study comparing two treatment approaches for chronic fatigue syndrome in adolescents
}

\author{
B Wright, B Ashby, D Beverley, E Calvert, J Jordan, J Miles, I Russell, C Williams
}

Arch Dis Child 2005;90:369-372. doi: 10.1136/adc.2003.046649

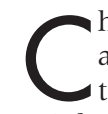
hronic fatigue syndrome (CFS) involves severe disabling fatigue that affects physical and mental functioning. ${ }^{1}$ Reported prevalence varies between $0.05 \%$ and $2 \%$ depending on definitions and methodologies. ${ }^{2}{ }^{3}$ There are significant short and long term effects on young people and their families, including long term school non-attendance. ${ }^{45}$ Most reported studies are not randomised, are from a variety of different clinical settings, and show variable outcomes: $5-20 \%$ being seriously incapacitated in the longer term, with larger numbers having residual symptoms. ${ }^{26-9}$

There is lack of consensus about the effectiveness of the main treatment approaches. These range from approaches that involve high levels of rest, through "pacing" to more active rehabilitation. More active rehabilitation has developed as a treatment focusing on graded rehabilitation, and more recently cognitive behavioural techniques. They are now more likely to integrate a range of approaches to address physiological, psychological, social, and systemic aspects of the syndrome.

Strong feelings about treatment can be expressed by proponents at either end of the spectrum, sometimes with criticism of alternative approaches. Some advocating active rehabilitation quote research saying that prolonged excessive inactivity has adverse consequences. ${ }^{10}$ Conversely advocates of prolonged rest who find support from internet sites, ${ }^{11}$ some specialist clinics, ${ }^{4}$ and some general practitioners ${ }^{12}$ believe active rehabilitation can be damaging. Criticism of overzealous rehabilitation can tend to undermine all rehabilitation, and criticism of rest can tend to undermine all energy management programmes. This polarisation of views conspires against healthy discussion on middle ground treatments. This makes open minded randomised controlled trials essential to provide evidence to guide treatment and restore confidence in treatment centres, particularly as new initiatives to establish centres of excellence unfold.

This study assesses the feasibility of a larger treatment trial comparing the effectiveness of the two current most common treatment approaches. We sought to explore the acceptability of treatments and the numbers needed to show a meaningful difference between treatments.

\section{METHODS}

The study was undertaken, with ethical committee approval, at York Hospital, which covers a population of 300 000. A total of 328 local professionals from health, social services, and education identified young people known to them with CFS or with more than two weeks off school because of physical symptoms but no clear diagnosis. These and any subsequent new cases identified over a 15 month period were assessed by a paediatrician (DWB). Those meeting the

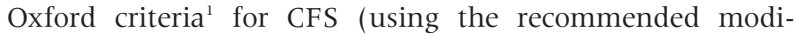
fication for children of three months' fatigue) were given further information about the study. Exclusions were other fatiguing medical conditions and pre-existing ongoing treatment for CFS. Informed consent was obtained from participants.

Young people were randomised to one of two treatment groups using remote randomisation at York University. This stratified for age, sex, and mobility. Over one year clinic appointments were weekly for one month, 2 weekly for the next three months, 3 weekly for two months, and 4 weekly for six months. Three clinicians (BW, CW, BA) conducted both treatment options using treatment manuals. The paediatrician (DWB) saw all young people every 12 weeks.

Research assessment interviews were conducted blind to treatment, by a separate researcher $(\mathrm{JJ})$ prior to treatment and at one year after treatment began.

Both treatment arms included:

- A strong emphasis on collaboration with patient and family

- Support and advice to establish a normal eating pattern, a balanced healthy diet, and healthy sleep patterns

- Cooperative work between child mental health professionals and paediatricians.

The two treatment arms were characterised in the following ways:

- "Pacing" is described in a document presented to the Chief Medical Officer's working group on CFS/ME. ${ }^{13}$ and included: (1) pacing activity to the changing needs and responses of the body by exercising to the point of tolerance, avoiding overexertion; (2) managing energy within an overall limit ("glass ceiling"); (3) resting when necessary, but avoiding total rest; (4) avoiding physically and/or emotionally stressful situations until ready; and (5) tailoring return to school to the needs of the young person,

Table 1 Treatment option by age group, sex, and length of illness

\begin{tabular}{|c|c|c|c|c|c|c|}
\hline \multirow{2}{*}{$\begin{array}{l}\text { Treatment } \\
\text { option (n) }\end{array}$} & \multicolumn{2}{|c|}{ Gender } & \multicolumn{3}{|l|}{ Age } & \multirow{2}{*}{$\begin{array}{l}\text { Median length of illnes } \\
\text { in months }\end{array}$} \\
\hline & Male & Female & $0-11$ & $12-14$ & $15-19$ & \\
\hline Pacing & 2 & 4 & 0 & 4 & 2 & 14.5 \\
\hline Stairway & 3 & 4 & 1 & 3 & 3 & 12.0 \\
\hline$p$ value & $1.00^{*}$ & & $1.00+$ & & & 0.248 \\
\hline
\end{tabular}

*Fisher's exact test.

†Mann-Whitney U test. 
taking careful heed of symptoms, the child, and the family.

- The STAIRway to Health programme involved a Structured TAilored Incremental Rehabilitation programme. This incorporated some aspects of previously researched approaches. ${ }^{14}{ }^{15}$ In particular time was spent:

- providing a holistic understanding of CFS that moved away from an exclusively physical or an exclusively psychological understanding of the illness

- explaining vicious cycles that exacerbate illness, including those of nutrition, sleep patterns, physical deconditioning, social isolation, educational estrangement, and emotional cycles (including loss of self-esteem and confidence)

- bolstering adaptive coping strategies and re-evaluating negative attributions about the illness and the future.

Collaboratively agreed targets were set around six areas: nutrition, activity, sleep, social activity, emotional factors, and school reintegration. The young person monitored these using a diary. Young people were not expected to do any activities they had not agreed.

As the treatment progressed, young people were encouraged to discuss constructively how their lifestyles, temperaments, and approaches to life may impact on illness or recovery. A tailored gradual return to school was planned where possible, as was a gradual return to normal social activity.

\section{Outcome measures}

The following five main outcome measures were used.

- Global health

- rated from the Child Health Questionnaire ${ }^{16}$ by the child

- rated by the clinician at the end of treatment

- Activity

- rated from the Child Health Questionnaire ${ }^{16}$ by the child

- rated by the paediatrician and child using the Young Person Functional Ability Scale ${ }^{17}$

- School attendance (percentage of possible days attended in six month periods)

- Fatigue on a self report measure (using the 14 item version $)^{18}$

- Emotional symptoms on self report measures

- depression $^{19}$

- anxiety. $^{20}$

Table 2 Mean scores for outcome measures before and after treatment

\begin{tabular}{|c|c|c|c|c|c|c|c|c|}
\hline & \multicolumn{4}{|l|}{ Pacing } & \multicolumn{4}{|c|}{ Stairway to health } \\
\hline & Mean (SD) & $\begin{array}{l}\text { 25th } \\
\text { centile }\end{array}$ & Median & $\begin{array}{l}\text { 75th } \\
\text { centile }\end{array}$ & Mean (SD) & $\begin{array}{l}25 \text { th } \\
\text { centile }\end{array}$ & Median & $\begin{array}{l}\text { 75th } \\
\text { centile }\end{array}$ \\
\hline \multicolumn{9}{|l|}{ Global health (1-5; higher score worse health) } \\
\hline Global health rating before treatment & $4.20(0.837)$ & 3.50 & 4.00 & 5.00 & $4.00(1.095)$ & 3.50 & 4.00 & 5.00 \\
\hline Global health score after treatment & $4.20(0.837)$ & 3.50 & 4.00 & 5.00 & $2.20(0.447)$ & 2.00 & 2.00 & 2.50 \\
\hline \multicolumn{9}{|c|}{ Child activity ratings ( $1-4$; higher score fewer difficulties, $4=$ no problems) } \\
\hline $\begin{array}{l}\text { Difficulty doing highly exertional activities } \\
\text { (before) child rated }\end{array}$ & $1.80(0.837)$ & 1.00 & 2.00 & 2.50 & $1.33(0.516)$ & 1.00 & 1.00 & 2.00 \\
\hline Difficulty doing highly exertional things (after) & $2.00(1.414)$ & 1.00 & 1.00 & 3.50 & $3.20(0.827)$ & 2.50 & 3.00 & 4.00 \\
\hline $\begin{array}{l}\text { Difficulty doing moderately exertional activities } \\
\text { such as swimming (before) }\end{array}$ & $2.80(1.304)$ & 1.50 & 3.00 & 4.00 & $1.83(1.169)$ & 1.00 & 1.50 & 2.50 \\
\hline $\begin{array}{l}\text { Difficulty doing moderately exertional activities } \\
\text { such as swimming (after) }\end{array}$ & $2.60(1.517)$ & 1.00 & 3.00 & 4.00 & $4.00(0)$ & 4.00 & 4.00 & 4.00 \\
\hline $\begin{array}{l}\text { Difficulty walking and climbing several flights } \\
\text { of stairs (before) }\end{array}$ & $3.00(0.707)$ & 2.50 & 3.00 & 3.50 & $2.67(1.366)$ & 1.00 & 3.00 & 4.00 \\
\hline $\begin{array}{l}\text { Difficulty walking and climbing several flights } \\
\text { of stairs (after) }\end{array}$ & $3.20(0.837)$ & 2.50 & 3.00 & 4.00 & $4.00(0)$ & 4.00 & 4.00 & 4.00 \\
\hline Difficulty climbing one flight of stairs (before) & $3.60(0.894)$ & 3.00 & 4.00 & 4.00 & $3.17(1.169)$ & 2.50 & 3.50 & 4.00 \\
\hline Difficulty climbing one flight of stairs (after) & $3.40(0.894)$ & 2.50 & 4.00 & 4.00 & $4.00(0)$ & 4.00 & 4.00 & 4.00 \\
\hline Difficulty getting in and out of bed (before) & $3.40(0.894)$ & 2.50 & 4.00 & 4.00 & $2.83(1.329)$ & 1.75 & 3.00 & 4.00 \\
\hline Difficulty Getting in and out of bed (after) & $3.80(0.447)$ & 3.50 & 4.00 & 4.00 & $4.00(0)$ & 4.00 & 4.00 & 4.00 \\
\hline \multicolumn{9}{|c|}{ Paediatrician activity ratings (YPAS $\left.{ }^{17}\right)(0-100 \% ; 100 \%$ is fully healthy and active) } \\
\hline Baseline Physical Activity Score (YPAS) & $67.00(18.23)$ & 52.5 & 75 & 77.5 & $52.50(22.75)$ & 31.25 & 55 & 75 \\
\hline Exit Physical Activity Score & $68.50(27.02)$ & 40 & 80 & 91.25 & $81.25(17.59)$ & 60 & 87.5 & 95.63 \\
\hline \multicolumn{9}{|c|}{ School attendance (percentage of possible half days in six month period) } \\
\hline $\begin{array}{l}\text { School attendance in the } 6 \text { months before } \\
\text { treatment as a percentage }\end{array}$ & $45.74(29.92)$ & 16.75 & 53.00 & 71.10 & $45.25(40.90)$ & 0.00 & 45.75 & 86.00 \\
\hline School attendance at the end of treatment & $28.12(31.82)$ & 0.00 & 16.20 & 62.20 & $73.00(37.53)$ & 49.50 & 89.50 & 95.75 \\
\hline $\begin{array}{l}\text { School attendance in the six months after } \\
\text { treatment concluded }\end{array}$ & $28.70(36.24)$ & 0.00 & 14.50 & 64.50 & $84.60(34.8)$ & 76.90 & 98.00 & 100.00 \\
\hline \multicolumn{9}{|l|}{ Fatigue scale ${ }^{18}(0-42$; higher score worse fatigue) } \\
\hline Fatigue score before treatment & $23.20(9.23)$ & 13.50 & 26.00 & 31.50 & $32.17(6.113)$ & 26.00 & 34.00 & 36.25 \\
\hline Fatigue score at the end of treatment & $18.00(6.519)$ & 12.00 & 18.00 & 24.00 & $14.00(9.582)$ & 6.25 & 14.00 & 21.75 \\
\hline \multicolumn{9}{|c|}{ Birleson Depression Scale ${ }^{19}(0-36$; higher score lower mood) } \\
\hline Depression score before treatment & $14.00(5.657)$ & 9.00 & 15.00 & 18.50 & $15.83(5.529)$ & 10.00 & 15.50 & 21.00 \\
\hline Depression score at the end of treatment & $12.60(6.580)$ & 7.50 & 15.00 & 16.50 & $10.67(4.844)$ & 7.50 & 11.00 & 13.50 \\
\hline \multicolumn{9}{|l|}{ Anxiety score ${ }^{20}(0-21 ;$ higher score more symptoms) } \\
\hline Anxiety score before treatment & $6.80(3.56)$ & 3.00 & 9.00 & 9.50 & $10.17(3.71)$ & 6.75 & 9.50 & 12.50 \\
\hline Anxiety score at the end of treatment & $6.60(4.73)$ & 2.00 & 7.00 & 11.00 & $6.00(3.63)$ & 3.00 & 6.50 & 9.25 \\
\hline
\end{tabular}


Table 3 Analyses of covariance for each outcome

\begin{tabular}{|c|c|c|c|c|}
\hline & $\begin{array}{l}\text { Difference }(95 \% \mathrm{Cl}) \\
\text { All differences show more } \\
\text { improvement in STAIRway } \\
\text { arm than pacing arm }\end{array}$ & $F(d f=1,8)$ & p value & $\mathrm{n}$ for $80 \%$ power \\
\hline $\begin{array}{l}\text { School attendance comparing six months prior to study to } \\
\text { last six months of treatment (percentage) }\end{array}$ & $45.1(-1.8$ to 92.0$)$ & 4.9 & 0.057 & 18 \\
\hline $\begin{array}{l}\text { School attendance comparing six months prior to study to } \\
\text { six months post study (percentage) }\end{array}$ & $56.1(6.3$ to 105.7$)$ & 6.8 & 0.032 & 14 \\
\hline Difficulty doing highly exertional activities (child rated)* & $1.46(-0.33$ to 3.25$)$ & 3.7 & 0.095 & 36 \\
\hline Difficulty doing moderately exertional activities such as swimming ${ }^{*}$ & $1.56(-0.20$ to 2.33$)$ & 4.4 & 0.075 & 20 \\
\hline Difficulty walking and climbing several flights of stairs* & $0.93(0.02$ to 1.84$)$ & 5.8 & 0.046 & 16 \\
\hline Difficulty climbing one flight of stairs* & $0.71(-0.18$ to 1.61$)$ & 3.5 & 0.10 & 26 \\
\hline Difficulty getting in and out of bed* & $0.31(-0.17$ to 0.78$)$ & 2.4 & 0.17 & 40 \\
\hline $\begin{array}{l}\text { Young Person Functional Ability Scale }{ }^{17} \text { (percentage score rated by } \\
\text { paediatrician) }\end{array}$ & $17.0(-17.0$ to 51.0$)$ & 1.3 & 0.28 & 56 \\
\hline $\begin{array}{l}\text { Anxiety score }{ }^{20} \text { (0-21 child rated anxiety subscale, Hospital } \\
\text { Anxiety and Depression Scale) }\end{array}$ & $-1.60(-8.31$ to 5.10$)$ & 0.30 & 0.60 & 260 \\
\hline Depression score $^{19}$ (0-36 Birleson Depression Rating Scale) & $-2.99(-10.0$ to 4.06$)$ & 1.0 & 0.36 & 86 \\
\hline Fatigue score ${ }^{18}(0-4214$ item version) & $-5.2(-19.8$ to 9.49$)$ & 0.67 & 0.44 & 120 \\
\hline $\begin{array}{l}\text { Global health rated by child (Child Health Questionnaire), } \\
1=\text { excellent, } 5=\text { poor }\end{array}$ & $-1.8(-0.94$ to -2.74$)$ & 23.4 & 0.002 & $10+$ \\
\hline \multicolumn{5}{|c|}{$\begin{array}{l}\text { Analysis uses the "before" score as covariate, and the treatment group as independent variable. The total sample size was } 11, \text { because of two dropouts. The } 95 \% \\
\text { confidence intervals }(\mathrm{CI}) \text { describe the difference with pacing subtracted from stairway. These show greater improvements across measures for the STAIRway arm. } \\
\text { The effects presented are for the effect of treatment, controlling for baseline score. In the } n \text { for power column, our data are used to estimate future study sample sizes } \\
\text { required for } 80 \% \text { power (alpha }=0.05 \text { ), assuming that the effect size was consistent with this study. } \\
\text { *Scale 0-4 with } 4 \text { being best score (fully healthy). For the first eight items positive scores represent greater improvements in activity and occupation for the } \\
\text { STAIRway arm. For the last four items negative scores represent greater reduction in negative symptoms for the STAIRway arm. } \\
\text { tCurrent sample size provided } 98 \% \text { power for significant effect. }\end{array}$} \\
\hline
\end{tabular}

\section{Analysis}

The data were analysed with SPSS using parametric and nonparametric bivariate statistics. For each parametric outcome measure, analysis of covariance was used, with the baseline score as a covariate and the treatment option being used as a predictor. As this was a pilot study, we were interested in finding a recommended future sample size that would be required to detect a difference equal to that found in this study. This was calculated for $80 \%$ power at $5 \%$ significance based on the non-centrality parameter from the current study. This assumes that the effect size in this study is an unbiased estimator of the effect size in the population. ${ }^{21}$

\section{RESULTS}

Fourteen young people had newly diagnosed CFS; one declined involvement in the study. Thirteen (age range 8.916.9 years) gave informed consent. They were all in mainstream schools and were incapacitated by CFS to the point of not being able to attend. Six had been unwell for less than 1 year, five for between 1 and 2 years, and two for longer than 2 years. All were markedly restricted in their ability to walk from the house, but none were permanently bed or wheelchair bound. Randomisation resulted in young people being distributed as in table 1 . The results are shown in tables 2 and 3.

At the end of the study $100 \%$ of children in the STAIRway to Health arm showed completely healthy scores for all activity up to and including moderate exertional activities. No child had any problems with bike riding, swimming, and similar activities. In the pacing arm, $60 \%$ had problems in all three of these activities and still had some difficulties getting around school, compared with no problems in the STAIRway arm. Forty per cent in the pacing group still had problems with bending and lifting.

\section{DISCUSSION}

Statistical significances found should be treated with caution given the small sample sizes. The pacing programme used showed little improvement in activity scores rated by child or clinician and a deterioration in school attendance, whereas activity and school attendance were improved markedly in the STAIRway to health arm. The differences were clinically large. Global health improved in both arms although more in the STAIRway arm than the pacing arm whether measured by child or clinician.

This study suggests that contrary to the fears of some, active rehabilitation does not appear to make young people worse if managed correctly, although a larger study would be needed to explore whether such problems may affect a minority.

The apparent acceptability of these treatments, with low drop out rates is encouraging. Only one child did not consent to the study. Two dropped out, one from each arm of the study. This represents 11 out of 14 (79\%) of those consecutively diagnosed and approached. The centre concerned was highly motivated to engage and work positively with families. Whether this could be transferred to clinic settings remains to be seen. One boy in the STAIRway arm received an antidepressant, a relatively low rate given reported use of up to $94 \%$ in one series. ${ }^{9}$ The study has been useful in the development of treatment manuals.

There are few RCTs looking at children under $18,{ }^{22}$ although work is underway in London and Holland. This study is too small to be conclusive, but shows that a larger study is feasible and that these treatments are acceptable to patients and families. We would strongly recommend a well designed and larger multicentre trial.

\section{ACKNOWLEDGEMENTS}

We thank Ben Alderson-Day and Natalie Clarke for assistance with administrative aspects of the study, and Shona McIlrae for help with editing.

\section{Authors' affiliations}

B Wright, B Ashby, E Calvert, J Jordan, C Williams, Lime Trees, Shipton Road, York, UK

D Beverley, York Hospital, Wigginton Road, York, UK

J Miles, I Russell, University of York, Heslington Lane, York, UK

Competing interests: none declared 
Correspondence to: Dr B Wright, Lime Trees, Shipton Road, York YO30 5RF, UK; barry.wright@sypct.nhs.uk

Accepted 2 November 2004

\section{REFERENCES}

1 Royal Colleges of Physicians, Psychiatrists and General Practitioners. Report of Working Party on Chronic Fatigue Syndrome. London: Royal Colleges of Physicians, 1996.

2 Wright JB, Cottrell D. Chronic fatigue syndrome in children. In: Lynch SPJ, ed. Psychosocial aspects of chronic fatigue syndrome. Baillieres Clinical Psychiatry 1997;3(3):449-71.

3 Chalder T, Goodman R, Wessely S, et al. Epidemiology of chronic fatigue syndrome and self reported myalgic encephalomyelitis in 5-15 year olds: a cross sectional study. BMJ 2003;327:654-5.

4 Dowsett EG Colby J. Long term sickness absence due to ME/CFS in UK schools: an epidemiological study with medical and educational implications. Journal of Chronic Fatigue Syndrome 1997;3:29-42.

5 Joyce J, Hotopf $M$, Wessely $S$. The prognosis of chronic fatigue and chronic fatigue syndrome: a systematic review. Q J Med 1997;90:223-33.

6 Chalder T, Tong J, Deary V. Family cognitive behaviour therapy for chronic fatigue syndrome: an uncontrolled study. Arch Dis Child 2002;86:95-7.

7 Khawaja SS, Van Boxel P. Chronic fatigue syndrome in childhood: a seven year follow up study. Psychiatric Bulletin 1998;22:198-202.

8 Bell DS, Jordan K, Robinson M. Thirteen-year follow-up of children and adolescents with chronic fatigue syndrome. Pediatrics 2001;107:994-8.

9 Patel MX, Smith DG, Chalder T, et al. Chronic fatigue syndrome in children: a cross sectional survey. Arch Dis Child 2003;88:894-8.
10 Sharpe $M$, Wessely S. Putting the rest cure to rest-again. BMJ 1998;316:796

11 Wright JB, Williams C. Management advice for children with chronic fatigue syndrome. A systematic study of information from the internet. Irish Journal of Psychological Medicine 1997;16(2):67-71.

12 Richards J, Smith F. Chronic fatigue syndrome in children and adolescents. Psychiatr Bull 1998;23:203-6.

13 Department of Health. A Report to the Chief Medical Officer of the Chronic Fatigue Syndrome CFS/ME Working Group. www.doh.gov.uk/cmo/ cfsreport (accessed 28 October 2003).

14 Wright B, Partridge I, Williams C. Management of chronic fatigue syndrome. Advances in Psychiatric Treatment 2000;6:145-52.

15 Wright JBD, Beverley DW. Chronic fatigue syndrome. Arch Dis Child 1998;79:368-74.

16 Landgraf JM, Maunsell E, Nixon-Speechley K, et al. Canadian-French, German, and United Kingdom versions of the Child Health Questionnaire (CHQ-PF50): methodology and preliminary item scaling results. Qual Life Res 1998;7:433-45.

17 Young Person's Functional Ability Scale. Association of Young People with ME, PO Box 650, Milton Keynes, MK22XD, UK.

18 Chalder T, Berelowitz G, Pawlikowska T, et al. Development of a fatigue scale. J Psychosom Res 1993;37:147-53.

19 Birleson P. The validity of depressive disorder and the development of a self rating scale: a research report. J Child Psychol Psychiatry 1981;22:73-88.

20 Zigmond AS, Snaith RP. The hospital anxiety and depression scale. Acta Psychiatr Scand 1983;67:361-70.

21 Murphy KR, Myors B. Statistical power analysis. Mahwah, NJ: Erlbaum, 1998.

22 NHS Centre for Reviews and Dissemination. Interventions for the management of CFS/ME. Effective Health Care 2002;7(4):1-12.

\section{IMAGES IN PAEDIATRICS}

\section{Toys and potentially lethal games}

A 15 year old was brought to our emergency department with mild headache after having been shot at contact range with an air pistol. Examination revealed a circular entry wound of $1 \mathrm{~cm}$ on the forehead without a corresponding exit wound. Neurologically there were no focal signs. Skull $x$ ray examination showed a radio-opaque foreign body in the frontal lobe. Computed tomography scan showed pellet fragments in the left frontal lobe with surrounding haemorrhage. The child was referred to the regional neurosurgeons for further management.

Air pistols are known to inflict potentially lethal injuries such as extensive brain damage, traumatic aneurysms, and penetrating injuries of the abdomen. ${ }^{1}$ There have been reported incidents of suicides and non-accidental injuries with air pistols. ${ }^{2}$ Shanon et al noted that $85 \%$ of the injuries, where the mode of injury was known, were self inflicted while playing with air guns; $12.7 \%$ of their patients had long term disabilities. ${ }^{3}$

Air pistols, despite their capacity to inflict hazardous injuries, are still used as toys and continue to be mishandled by children. Increased public awareness of the hazardous nature of air pistols is
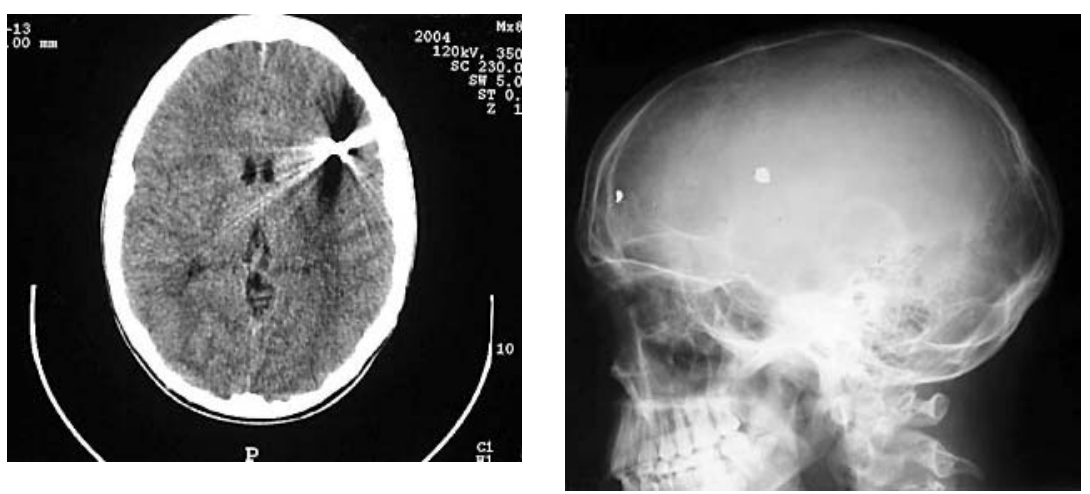

required to prevent their mishandling. Educating the public in appropriate handling and supervision of children while playing with these deceptively harmless but lethal toys combined with a stricter legislation could reduce the incidence of these injuries. Physicians should be aware that some of these patients may appear clinically stable with minimal external injuries and still have significant trauma to the internal organs.

R Thalava

Royal Orthopaedic Hospital, Birmingham, UK

R Puttha

Chelsea and Westminster Hospital, London, UK
Correspondence to: Dr R Puttha, Department of Paediatrics, St George's Hospital, Blackshaw Road, London SO17 7BJ, UK; radput3@yahoo.co.uk

\section{References}

1 Bhattacharyya N, Bethel CA, Caniano DA, et al. The childhood air gun: serious injuries and surgical interventions. Pediatr Emerg Care 1998;14:188-90.

2 Campbell-Hewson GL, D'Amore A, Busuttil A. Non-accidental injury inflicted on a child with an air weapon. Med Sci Law 1998;38:173-6.

3 Shanon A, Feldman W. Serious childhood injuries caused by air guns. CMAJ $1991 ; 144: 723-5$. 